Research Article

\title{
Primary Investigation on Equivalent Anchoring Method of Jointed Rock Mass Tunnel and Its Engineering Application
}

\author{
Min Gao $\mathbb{D}^{1}$ and Shanpo Jia $\mathbb{D}^{2}$ \\ ${ }^{1}$ State Key Laboratory of Coastal and Offshore Engineering, Dalian University of Technology, Dalian 116024, China \\ ${ }^{2}$ Institute of Unconventional Oil \& Gas, Northeast Petroleum University, Daqing 163318, China \\ Correspondence should be addressed to Shanpo Jia; jiashanporsm@163.com
}

Received 30 November 2019; Revised 14 May 2020; Accepted 29 May 2020; Published 3 July 2020

Academic Editor: Chunshun Zhang

Copyright (c) 2020 Min Gao and Shanpo Jia. This is an open access article distributed under the Creative Commons Attribution License, which permits unrestricted use, distribution, and reproduction in any medium, provided the original work is properly cited.

\begin{abstract}
Rock bolts, one of the main support structures of the tunnel, can improve the stress state and mechanical properties of the surrounding rocks. The rock bolts are simulated by bar or beam elements in present numerical calculations for most $2 \mathrm{D}$ tunnel models. However, the methods of simulating rock bolt in three-dimensional models are rarely studied. Moreover, there are too many rock bolts in the long-span tunnel, which are hardly applied in the $3 \mathrm{D}$ numerical model. Therefore, an equivalent anchoring method for bolted rock masses needs to be further investigated. First, the jointed material model is modified to simulate the anisotropic properties of surrounding rock masses. Then, based on the theoretical analysis of rock bolts in reinforcing mechanical properties of the surrounding rock masses, the equivalent anchoring method of the jointed rock mass tunnel is numerically studied. The equivalent anchoring method is applied to the stability analysis of a diversion tunnel in Western China. From the calculation results, it could be found that the reinforcement effect of rock bolts could be equivalently simulated by increasing the mechanical parameter value of surrounding rocks. For the jointed rock mass tunnel, the cohesion and internal friction angle of the surrounding rocks are improved as 1.7 times and 1.2 times of the initial value, which can simulate the reinforcement effect of rock bolts. Comparing with analytical results, the improved internal friction angle is nearly consistent with analytical result. The reinforcement effect of rock bolts is simulated obviously when the mechanical parameters of surrounding rocks are increased simultaneously. The engineering application shows that the equivalent anchoring method can reasonably simulate the effect of rock bolts, which can provide reference for stability analysis of three-dimensional tunnel simulations.
\end{abstract}

\section{Introduction}

Rock bolts are widely used in tunneling, mining, and other underground engineering projects for more than 100 years, which can improve the strength and stiffness of surrounding rock masses. The finite element method has been extensively employed to study the mechanism of bolting, and the rock bolts are mostly simulated by bar or beam elements for twodimensional models. However, the three-dimensional rock bolt element of FEM is rarely studied and used in 3D tunnel simulations. Moreover, for the long-span tunnel, the rock bolts are numerous and hardly installed in the 3D tunneling models. Therefore, an equivalent simulation method for bolted rock masses that will simplify the difficulty of the numerical calculation needs to be further investigated.
Rock bolt is a part of a series of support methods, denoted as "rock reinforcement system." The mechanism of the bolted rock masses is widely investigated by analytical analysis, laboratory and field tests, and numerical simulations, which includes the bonding capacity of rock bolts and the interfaces properties between the bolts and rocks [1-7]. Some investigations focus on the constitutive relationships of the bolted rock masses. Chen proposed an equivalent constitutive model for jointed rock masses reinforced by fully grouted bolts, and the model was implemented in a finite element program [8]. Densie regarded the bolted rock masses as a homogenized anisotropic medium and proposed an elastoplastic constitutive model for bolted rock masses [9]. Carranza presented a closed-form solution for stress and displacement distributions around a circular tunnel 
excavated in elastic material and reinforced by rock bolts [10]. Maghous proposed a three-dimensionally theoretical and numerical model for the behavior of tunnels reinforced by rock bolts [11]. Many similar studies have been published on the constitutive model of the bolted rock masses from different viewpoints [12-16]. Though the constitutive models can accurately reflect the mechanical properties of the bolted rock masses, the implementation and subsequent computational process are quite difficult and time-consuming.

To simplify the numerical calculations of the bolted rock masses, many investigations assume that the constitutive model of the rocks is not changed after the bolts installed, but the mechanical parameters of the bolted rock masses are strengthened comparing with the rock masses before rock bolts are applied [17-19]. Most published literature indicated that the rock reinforcement effect could be equivalently simulated by improving the parameters of surrounding rock masses $[3,15,20,21]$ but the increased value of the parameters such as elastic modulus, cohesive, and internal friction angles of the surrounding rock masses needs to be further investigated.

The existing experimental results have indicated that the layered rocks display a strong anisotropy of strength and deformation, which is usually controlled by the orientation of bedding planes [22-25]. The anisotropic properties of the layered rocks were investigated by experiments, analytical solutions, and numerical simulations in the past [26-34]. However, the surrounding rock masses are assumed to be isotropic in most numerical modeling. Therefore, a reasonable constitutive relationship of the layered rock masses should also be needed before investigating the equivalent anchoring method.

In our study, the jointed material model is modified by introducing the anisotropic elastic matrix into the model, and the modified model is numerically implemented and verified. Based on the modified jointed material model, the reinforcement effect of rock bolts installed during the excavation process of the jointed rock mass tunnel is investigated. The equivalent simulation method of improving the parameters of the surrounding rocks for the bolted rock masses is studied through a series of numerical simulations. Then, the equivalent anchoring method is adopted for the stability analysis of a division tunnel in Western China.

\section{Modified Jointed Material Model}

2.1. Anisotropic Elastic Parameters. Figure 1 shows the five elastic constants, $E_{1}$ and $v_{1}$ are the elastic modulus and Poisson's ratio parallel to transversely isotropic surfaces, and $E_{2}, v_{2}$, and $G_{2}$ are the elastic modulus, Poisson's ratio, and shear modulus perpendicular to transversely isotropic surfaces, respectively. The five elastic constants can be determined by laboratory tests, such as uniaxial compression, triaxial compression, and Brazilian tests. Amadei and Pan [30] suggested that the stress matrix $\left(\sigma_{x}, \sigma_{y}, \sigma_{z}, \tau_{y z}, \tau_{z x}, \tau_{x y}\right)$ and strain matrix $\left(\varepsilon_{x}, \varepsilon_{y}, \varepsilon_{z}, \gamma_{y z}, \gamma_{z x}, \gamma_{x y}\right)$ of the layered rock mass were related not only to the five elastic parameters $\left(E_{1}, \nu_{1}, E_{2}, v_{2}, G_{2}\right)$ but also to the dip angle of the joint set (the angle between the bedding planes and horizontal line: $\theta$ ):

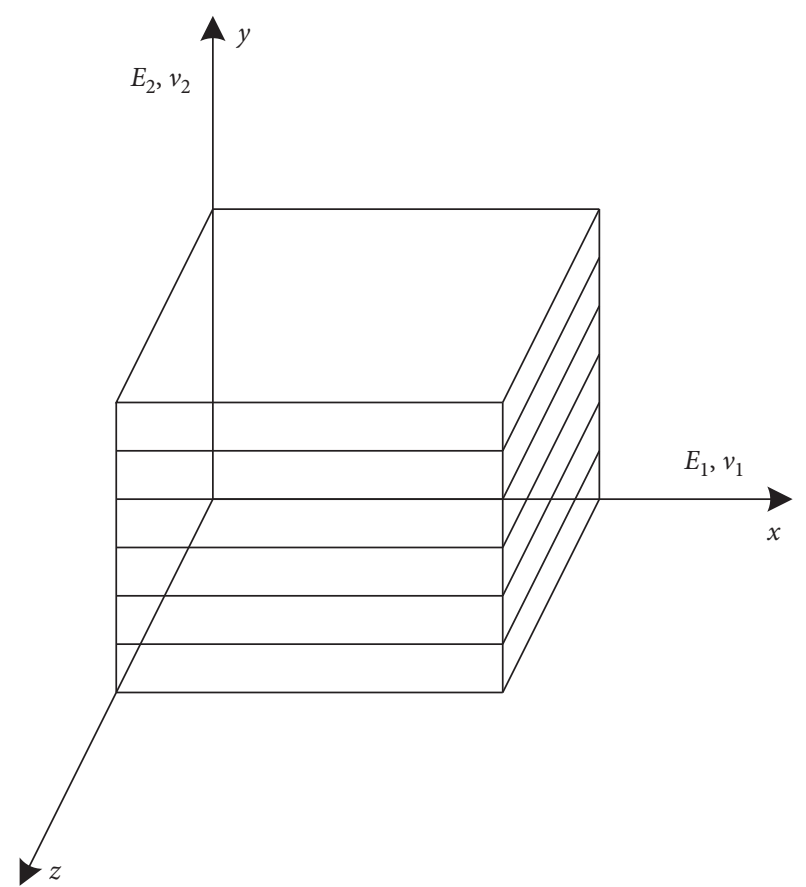

FIGURE 1: Transversely isotropic model.

$$
\left[\begin{array}{c}
\varepsilon_{x} \\
\varepsilon_{y} \\
\varepsilon_{z} \\
\gamma_{y z} \\
\gamma_{z x} \\
\gamma_{x y}
\end{array}\right]=\left[\begin{array}{llllll}
a_{11} & a_{12} & a_{13} & a_{14} & a_{15} & a_{16} \\
a_{21} & a_{22} & a_{23} & a_{24} & a_{25} & a_{26} \\
a_{31} & a_{32} & a_{33} & a_{34} & a_{35} & a_{36} \\
a_{41} & a_{42} & a_{43} & a_{44} & a_{45} & a_{46} \\
a_{51} & a_{52} & a_{53} & a_{54} & a_{55} & a_{56} \\
a_{61} & a_{62} & a_{63} & a_{64} & a_{65} & a_{66}
\end{array}\right]\left[\begin{array}{c}
\sigma_{x} \\
\sigma_{y} \\
\sigma_{z} \\
\tau_{y z} \\
\tau_{z x} \\
\tau_{x y}
\end{array}\right] .
$$

The relationship between axial stress $\left(\sigma_{y}\right)$ and strain $\left(\varepsilon_{x}, \varepsilon_{y}, \varepsilon_{z}\right)$ can be expressed as

$$
\begin{aligned}
& \varepsilon_{x}=a_{12} \sigma_{y}, \\
& \varepsilon_{y}=a_{22} \sigma_{y}, \\
& \varepsilon_{z}=a_{23} \sigma_{y},
\end{aligned}
$$

where $a_{12}, a_{22}$, and $a_{23}$ are the functions of the jointed surface direction $\theta$ and the five elastic parameters $\left(E_{1}, v_{1}, E_{2}, v_{2}, G_{2}\right)$, through the following relationships:

$$
\begin{aligned}
& a_{12}=\left(\frac{1}{E_{1}}+\frac{1}{E_{2}}+\frac{2 \nu_{2}}{E_{2}}-\frac{1}{G_{2}}\right) \sin ^{2} \theta \cos ^{2} \theta-\left(\frac{\nu_{2}}{E_{2}}\right), \\
& a_{22}=\left(\frac{1}{E_{1}} \sin ^{4} \theta\right)+\left(\frac{1}{E_{2}} \cos ^{4} \theta\right)+\left(\frac{1}{G_{2}}-\frac{2 \nu_{2}}{E_{2}}\right) \sin ^{2} \theta \cos ^{2} \theta, \\
& a_{23}=-\frac{\nu_{2}}{E_{2}} \cos ^{2} \theta-\frac{\nu_{1}}{E_{1}} \sin ^{2} \theta .
\end{aligned}
$$

Then, the elastic parameters of each joint dip angle are given by 


$$
\begin{gathered}
E=\frac{1}{a_{22}}, \\
v_{y z}=-\frac{a_{23}}{a_{22}}, \\
v_{y x}=-\frac{a_{12}}{a_{22}} .
\end{gathered}
$$

Both the elastic modulus and Poisson's ratio vary as functions of the joint dip angles:

$$
\left\{\begin{array}{l}
E(\theta)=f_{1}(\theta) \\
\nu(\theta)=f_{2}(\theta)
\end{array}\right.
$$

The anisotropic elastic parameters of the layered sandstone were measured through the uniaxial tests by Zhang [35]; then, the elastic parameters of the layered sandstone with different inclination angles can be predicted by using equation (4) theoretically. Table 1 shows the comparison of the experimental and theoretical results of elastic parameters of the layered sandstone. It can be found that the difference of the elastic modulus of the layered sandstone with different inclination angles between theoretical and experimental value is negligible, and the biggest deviation is $1.68 \%$. However, the difference of Poisson's ratio is a little bigger; the biggest deviation reaches $25.13 \%$. As a whole, the elastic parameters of the layered rock mass with different inclination angles predicted by using equation (4) are close to the experimental results.

2.2. Modified Joint Material Model. The jointed material model employed allows for the opening and frictional sliding of the joints. Additionally, the model includes a bulk material failure mechanism based on the Drucker-Prager failure criterion. The elastic matrix in jointed material model is isotropic, just having two independent elastic parameters (elastic modulus and Poisson's ratio). To consider the anisotropic nature of the jointed rock mass, the jointed material model has been modified by introducing the anisotropic parameters of the layered rock mass (equations (1)-(7)). The elastic matrix should be modified by equation (1), which can simulate the elastic properties of the layered rock mass with different inclination angles. The FORTRAN language is utilized for the model implementation.

2.3. Model Verification. Figure 2 presents the geometry and basic condition of the strip foundation on layered rock mass discretized into a $2 \mathrm{D}$ model $(10 \mathrm{~m} \times 10 \mathrm{~m})$. The width of the strip foundation is $2 \mathrm{~m}$, and the pressure on the layered rock is $50 \mathrm{kPa}$. The basic properties of the rock matrix are elastic modulus of $E_{1}=20 \mathrm{GPa}$ and $E_{2}=30 \mathrm{GPa}$, Poisson's ratio of $v_{1}=0.20$ and $v_{2}=0.30$, shear modulus of $G_{2}=9.68 \mathrm{GPa}$, and density of $2.3 \times 10^{3} \mathrm{~kg} / \mathrm{m}^{3}$. Soft interfaces have a normal stiffness of $7.5 \mathrm{GPa} / \mathrm{m}$, and tangential stiffness of $5 \mathrm{GPa} / \mathrm{m}$. The joint connectivity rate is 1 , and joint spacing is $0.1 \mathrm{~m}$.

Figures 3 and 4 present the results of von Mises stress and displacement of the strip foundation which is related to the changes of dip angle. The distribution of stress and deformation is symmetric for horizontal layered rock mass and vertical layered rock mass and asymmetrical for other dip angles of soft interfaces. The curves of stress and displacement of the selected measuring point and their relation with the dip angle are shown in Figure 5. At the dividing dip angle of $90^{\circ}$, the curves are symmetric within the range $\left[0^{\circ}, 180^{\circ}\right]$, and node displacement tends to be minimum in the vicinity of $90^{\circ}$. Thus, the modified model can effectively depict the anisotropic characteristics of the layered rock masses.

\section{Primary Investigations on the Equivalent Anchoring Method}

\subsection{Theoretical Analysis of Equivalent Reinforcement of Rock Bolts}

3.1.1. Equivalent Cohesion of Surrounding Rock Masses. It assumes that the surrounding rocks are well integrated, incomplete development of bedding planes, isotropic, and axially symmetric. Then, the surrounding rock masses of circular tunnel will be spiral failure after excavation. Two sets of slip lines $(\beta= \pm((\pi / 4)+(\varphi / 2)))$ will be generated in the plastic zone. The body of rock bolt will act as a "pin effect" to increase the shear strength of failure surfaces because of the generated slip lines. From the experimental results by Dulacska [36], it can be obtained that

$$
F=\frac{2 F_{\max } \beta}{\pi}
$$

where $F$ is the shear stress of rock bolt and $F_{\max }$ is the maximum shear stress of rock bolt. According to the von Mises failure criterion, $F_{\max }$ can be expressed as $F_{\max }=$ $\left(\pi d^{2} \sigma_{s} / 4 \sqrt{3}\right.$ ) for the condition of pure failure. $d$ is the diameter of rock bolt and $\sigma_{s}$ is the tensile strength of rock bolt.

The shear strength of the failure surfaces is enhanced due to the effect of rock bolt; therefore, the equivalent cohesion of the bolted rock masses can be expressed as

$$
c_{0}^{\prime}=c_{0}+\frac{\pi d^{2} \sigma_{s}\left((1 / 2)+\left(\varphi_{0} / \pi\right)\right) \sin \left((\pi / 4)+\left(\varphi_{0} / 2\right)\right)}{4 \sqrt{3} s_{l} s_{c}},
$$

where $c_{0}$ and $\varphi_{0}$ are the initial cohesion and internal friction angle of surrounding rock masses and $s_{l}$ and $s_{c}$ are the axial and circumferential spacing of rock bolts along the tunnel, which can be seen in Figure 6 .

3.1.2. Equivalent Internal Friction Angle of Surrounding Rock Masses. The mechanical parameters of rock masses and rock bolts both have an impact on the equivalent strength of the bolt-rock composite structure. According to the bolt density factor proposed by Indraratna [17], there is

$$
\alpha=\frac{d \pi \eta D}{2 s_{l} s_{c}}=\frac{d \pi \eta}{s_{l} \gamma},
$$

where $\gamma$ is the circumferential angle between the rock bolts, $D$ is the diameter of tunnel, and $\eta$ is the friction coefficient between rock bolt and rock mass, which relates to the surface roughness of rock bolt. When the threaded rock bolts are adopted, $\eta=\tan \varphi_{0}$; otherwise, $\eta=\tan \left(\varphi_{0} / 2\right)$. 
TABLE 1: Comparison between theoretical and experimental results ([36]).

\begin{tabular}{lccccccc}
\hline \multirow{2}{*}{ Group no. } & \multirow{2}{*}{ Dip angle } & \multicolumn{3}{c}{ Elastic modulus, $E(\mathrm{GPa})$} & \multicolumn{3}{c}{ Poisson's ratio, $v$} \\
& & Test value & Theoretical value & Deviation (\%) & Experimental value & Theoretical value & Deviation (\%) \\
\hline 1 & 0 & 24.39 & 24.39 & 0 & 0.179 & 0.164 & 8.24 \\
2 & 22.5 & 25.33 & 24.93 & 1.59 & 0.227 & 0.170 & 25.13 \\
3 & 45 & 27.62 & 27.61 & 0.02 & 0.250 & 0.195 & 0.244 \\
4 & 67.5 & 34.09 & 33.52 & 1.68 & 0.256 & 4.63 \\
5 & 90 & 37.79 & 37.79 & 0.01 & 0.254 & 0.279 \\
\hline
\end{tabular}

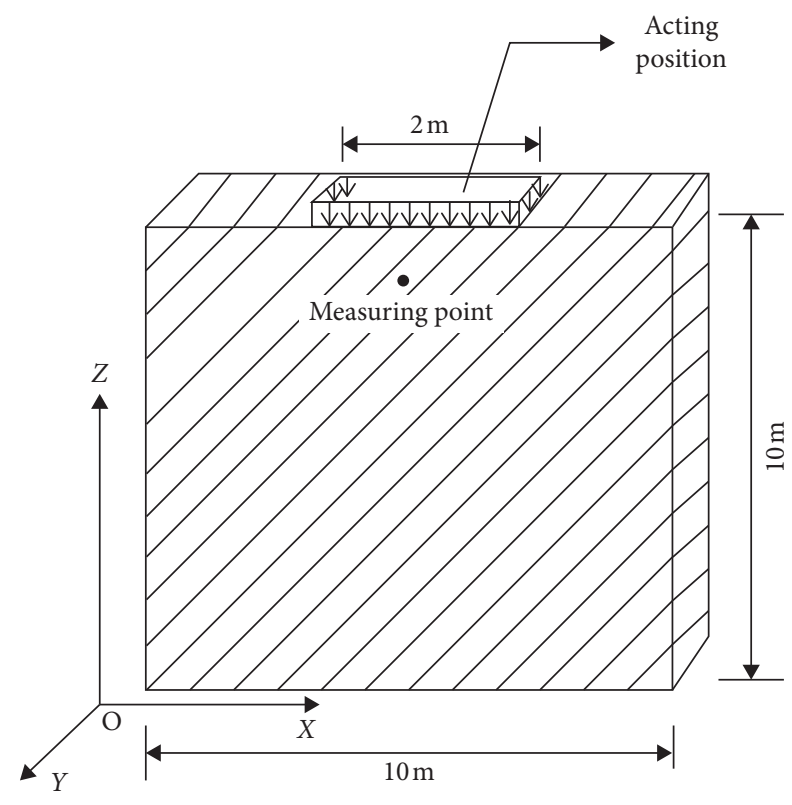

FIgURE 2: Schematic of the strip foundation model.

Based on the theory of fully grouted anchor, the same deformation will be generated by rock bolts and surrounding rocks after rock bolts installed. At this time, the shear stress generated at the surface of rock bolts prevents the surface deformation of surrounding rocks. This kind of reinforcement performs as the compressive strength $\left(\sigma_{c}^{*}\right)$ of surrounding rocks increased. Therefore, the equivalent compressive strength of the bolt-rock composite structure can be expressed as

$$
\sigma_{c}^{*}=\frac{2(1+\alpha) \mathcal{c}_{0} \cos \varphi_{0}}{1-\sin \varphi_{0}} .
$$

Assume that the bolt-rock composite structure satisfies the Mohr-Coulomb yield criterion. The gradient of the yield locus in principle stress coordinate system before and after the bolts supporting can be defined as $f_{0}$ and $f_{0}^{\prime}$, expressed as

$$
\begin{aligned}
& f_{0}=\left(\frac{1+\sin \varphi_{0}}{1-\sin \varphi_{0}}\right), \\
& f_{0}^{\prime}=\left(\frac{1+\sin \varphi_{0}^{\prime}}{1-\sin \varphi_{0}^{\prime}}\right) .
\end{aligned}
$$

The intercept of gradient $f_{0}^{\prime}$ increases after rock bolts are applied; combining with density factor of rock bolts, this variation relationship can be expressed as

$$
f_{0}^{\prime}=(1+\alpha) f_{0} \Longrightarrow\left(\frac{1+\sin \varphi_{0}^{\prime}}{1-\sin \varphi_{0}^{\prime}}\right)=(1+\alpha)\left(\frac{1+\sin \varphi_{0}}{1-\sin \varphi_{0}}\right)
$$

Equation (11) has been verified by Intraratna's experiments [17], the equivalent internal friction angle of the boltrock composite structure can be obtained through solving equation (11):

$$
\varphi_{0}^{\prime}=\sin ^{-1}\left[\frac{\left(1+\sin \varphi_{0}\right) \alpha+2 \sin \varphi_{0}}{\left(1+\sin \varphi_{0}\right) \alpha+2}\right] .
$$

3.1.3. Equivalent Elastic Modulus of Surrounding Rock Masses. Since the elastic modulus $\left(E_{b}\right)$ of the rock bolt is much larger than the elastic modulus $\left(E_{0}\right)$ of surrounding rocks, therefore, the codeformation between rock bolts and surrounding rocks will make a difference. For hard rock condition, the rock bolts have little impact on deformation parameters of surrounding rocks, and the deformation parameters have little impact on the evaluation of surrounding rocks stability. It can be assumed that Poisson's ratio is unchanged after rock bolts are applied, and the bolted rock masses are isotropic. According to the experimental results of Carranza [10], the equivalent elastic modulus of surrounding rock masses can be expressed as

$$
E_{0}^{\prime}=E_{0}+\frac{E_{b} \pi d^{2}}{4 s_{l} s_{c}} .
$$

\subsection{Numerical Studies on the Equivalent Anchoring Method of Jointed Rock Mass Tunnel}

3.2.1. Numerical Model and Calculation Parameters. The excavation process of a jointed rock masses tunnel is numerically simulated by different configurations including supporting with rock bolts and without rock bolts and improving the equivalent mechanical parameters of surrounding rocks (the zone of three times to five times of the tunnel diameter). The plastic zone of surrounding rocks and the displacement of key points (tunnel vault and tunnel floor) are compared with different configurations. The cohesion and internal friction angle of surrounding rocks are selected as the parameters for equivalent supporting by improving its initial value.

The size of numerical model is $60 \mathrm{~m} \times 60 \mathrm{~m}$, and the diameter of tunnel is $10 \mathrm{~m}$. The inclination angle of the jointed rocks is $\theta=30^{\circ}$. It assumes that the numerical model 


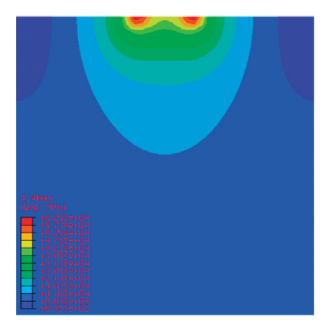

$0^{\circ}$

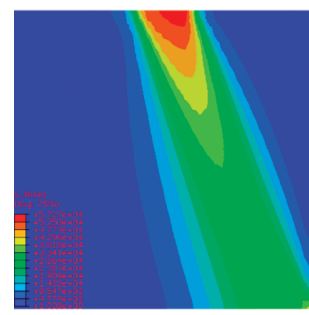

$100^{\circ}$

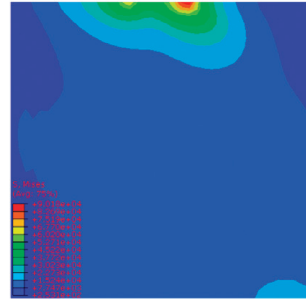

$20^{\circ}$

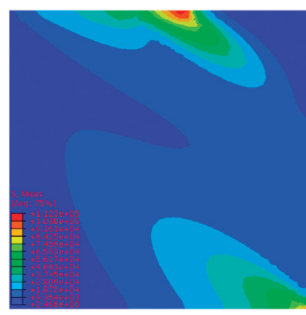

$120^{\circ}$

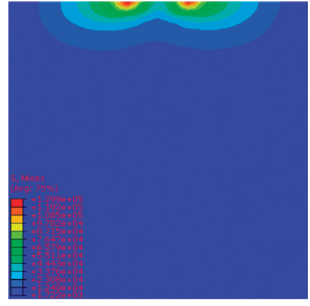

$40^{\circ}$

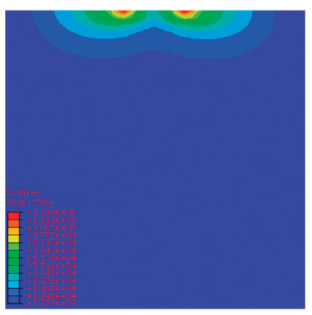

$140^{\circ}$

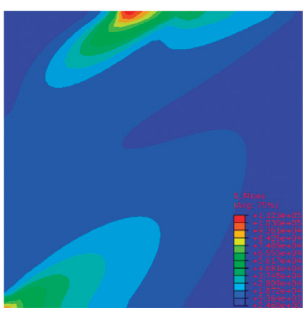

$60^{\circ}$

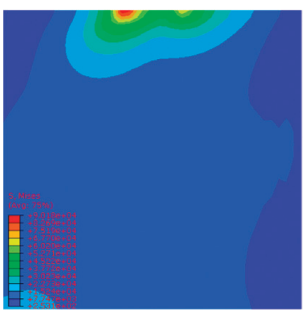

$160^{\circ}$

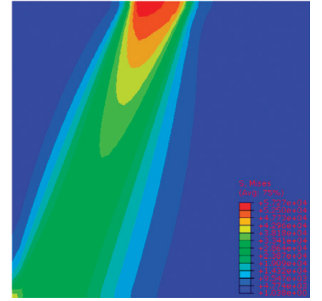

$80^{\circ}$

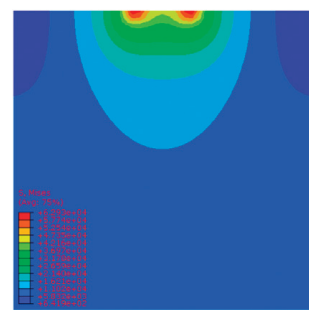

$180^{\circ}$

FIgURE 3: Distribution of von Mises stress in the strip foundation (Pa).

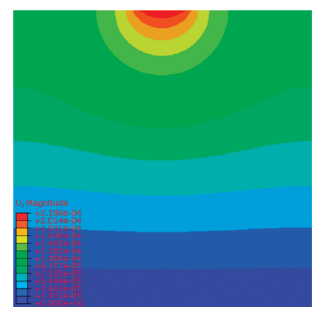

$0^{\circ}$

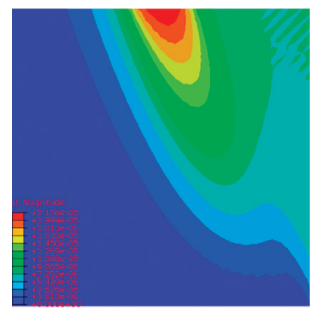

$100^{\circ}$

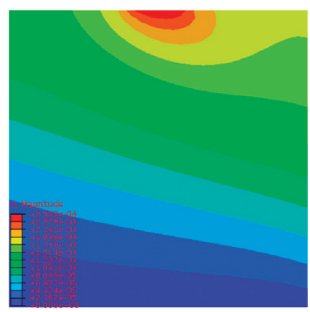

$20^{\circ}$

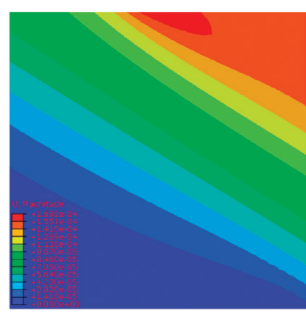

$120^{\circ}$

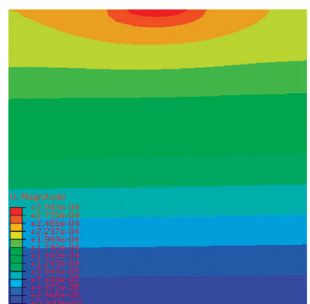

$40^{\circ}$

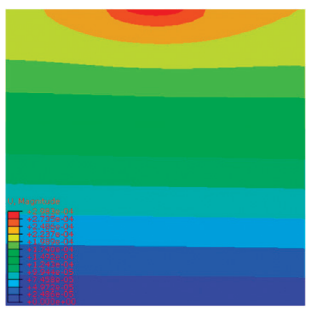

$140^{\circ}$

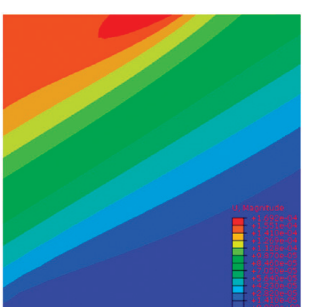

$60^{\circ}$

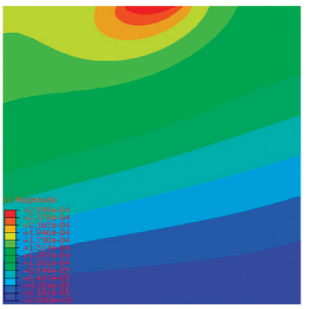

$160^{\circ}$

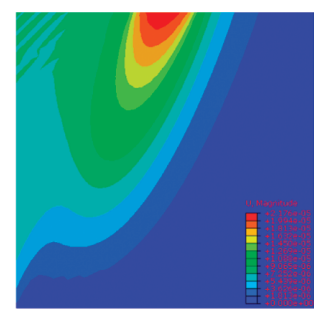

$80^{\circ}$

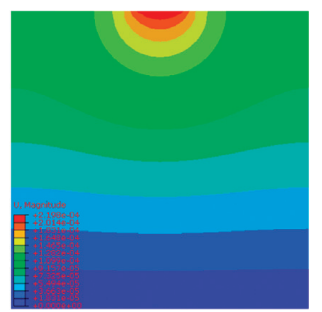

$180^{\circ}$

Figure 4: Distribution of displacement in the strip foundation (m).

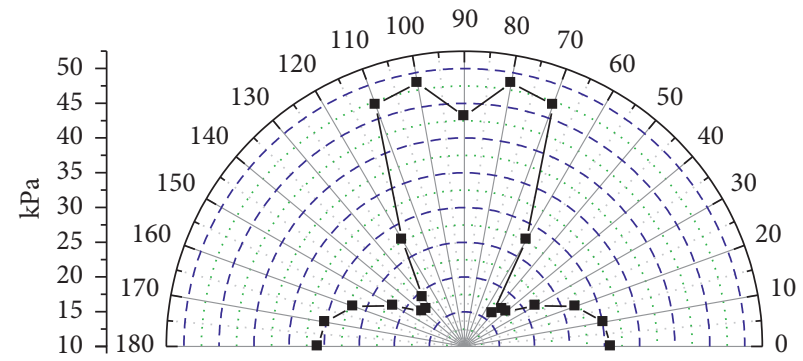

(a)

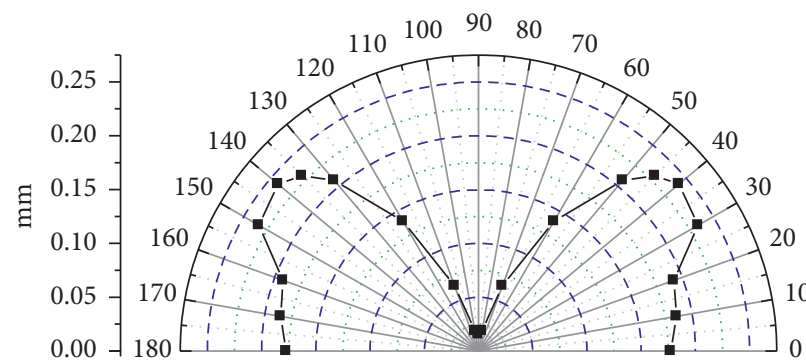

(b)

FIgURE 5: Stress and displacement of the measuring point changing with dip angle. (a) von Mises stress. (b) Displacement. 


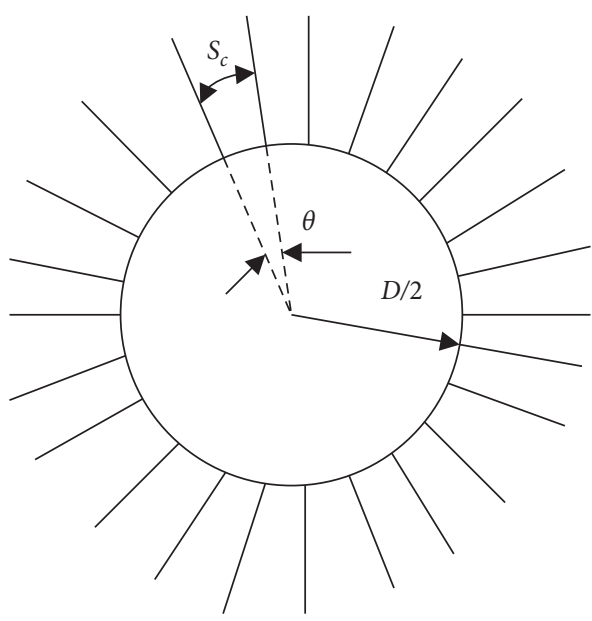

(a)

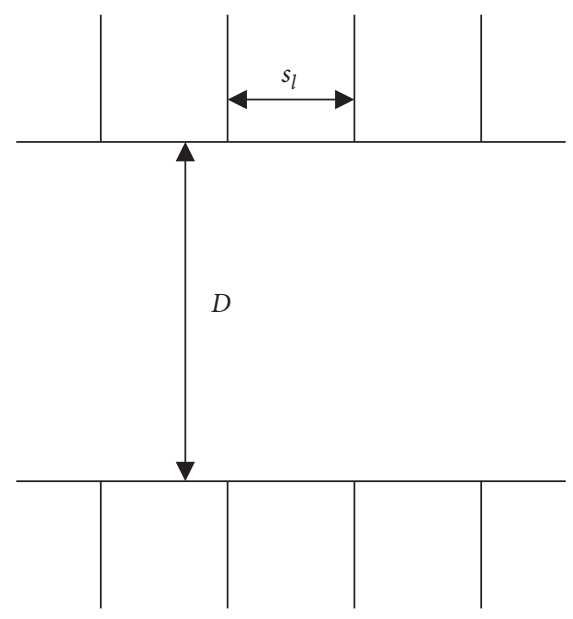

(b)

Figure 6: Schematic of tunnel supports. (a) Cross section of tunnel. (b) Longitudinal section of tunnel.

is under isotropic stress field of $4 \mathrm{MPa}$ along the $X$ and $Y$ directions of the model's boundary, and the bottom constraints of the model are fixed. Figure 7 is the diagram of the numerical model. In order to simplify the numerical model, the bar element and beam element are adopted to simulate the rock bolt and lining, respectively. The thickness of lining is $0.4 \mathrm{~m}$. The diameter of rock bolts is $25 \mathrm{~mm}$. The range interval distance of rock bolts is $1.3 \mathrm{~m}$, and the rock bolts are applied perpendicular to the tunnel cycle. The modified jointed material model is adopted for the surrounding rocks. Table 2 lists the mechanical parameters of the surrounding rocks, rock bolts, and lining.

3.2.2. Numerical Results and Analysis. The plastic zone can reflect stability and failure of the surrounding rock masses. Figure 8 shows the plastic zone of surrounding rocks after excavation of different configurations. Comparing Figures $8(\mathrm{a})$ and $8(\mathrm{~b})$, it can be found that the size and range of plastic zone supporting with rock bolts are obviously smaller than those without rock bolts installed, and the range of the plastic zone is directional which related to the bedding plane angle. It demonstrates that the rock bolts play an important role in controlling deformation and failure area of the surrounding rock masses.

Figures $8(\mathrm{c}) \sim 8(\mathrm{e})$ are the plastic zone of surrounding rock mass under equivalent supporting by taking mechanical parameters of surrounding rocks as $1.7 c, 1.3 \varphi$, and $1.3(c, \varphi)$, respectively. Comparing with Figure 8(b), it can be found that the plastic zone of surrounding rocks by equivalent supporting is basically analogous with the plastic zone of Figure $8(\mathrm{~b})$. Therefore, the equivalent supporting method can simulate the reinforcement effect of rock bolts for jointed rock mass tunnel. The equivalent mechanical parameter of cohesion is taken as $1.7 c$ to accurately simulate the reinforcement effect of rock bolts for jointed rock mass tunnel. However, the internal friction angle of surrounding rocks is only taken as $1.3 \varphi$. Obviously, it can be found that degree of sensitivity to simulate the reinforcement effect of rock bolts through improving the equivalent mechanical parameters of surrounding rocks is different, and the most sensitivity parameter is the internal friction angle and then cohesion.

The plastic zone of surrounding rocks cannot roundly reflect the reinforcement effect of rock bolts simulated by equivalent supporting. The vertical displacement of dome and horizontal displacement of arch foot are selected as the comparison objects. The numerical results can be seen in Tables 3-5. The numerical results of supporting with and without rock bolts installed are also given in all the tables.

In Tables 3-5, it can be seen that improving the parameters of surrounding rocks can simulate the reinforcement effect of rock bolts for jointed rock mass tunnel, but the improved value of each parameter is different. The value of cohesion and internal friction angle improved independently are 1.7 times and 1.2 times of the initial value, which can equivalently simulate the reinforcement effect of rock bolts. It also can be found that the degree of sensitivity to simulate the reinforcement of rock bolts by improving the mechanical parameters of surrounding rocks is different. The most sensitivity parameter is internal friction angle and then cohesion. This finding is consistent with the analysis of plastic zone distribution of surrounding rocks. When the equivalent parameter of cohesion is taken by $1.7 c$, the vertical displacement of dome is close to the result supporting by rock bolts, and the difference of the horizontal displacement of arch foot between equivalent supporting and supporting with rock bolts is $10.8 \%$. With the increasing of cohesion, the displacement of lining is decreased. When the equivalent parameter of internal friction angle is taken by $1.2 \varphi$, both the vertical displacement of dome and the horizontal displacement of arch foot are close to the result calculated by supporting with rock bolts. Therefore, it can simulate the reinforcement effect of rock bolts vividly.

Table 5 shows that when the shear strength parameters of surrounding rocks are increased by 1.1 times the initial value, the result of vertical displacement of lining vault is very closed to the result calculated by supporting with rock 


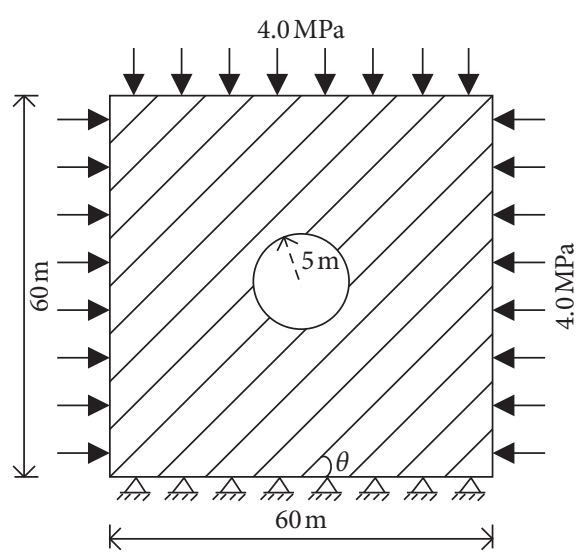

(a)

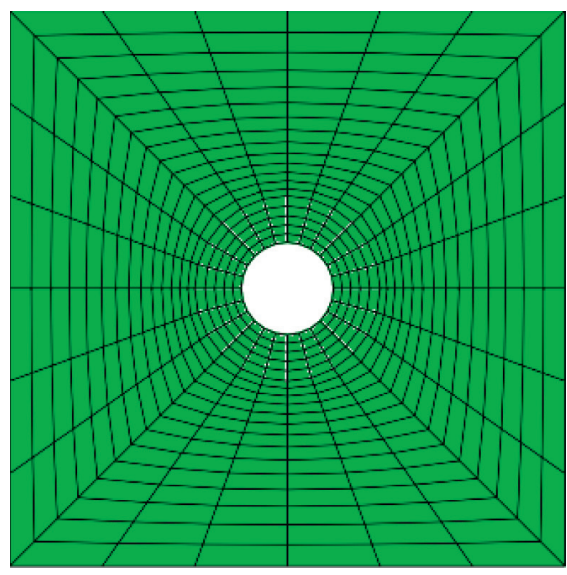

(b)

Figure 7: Diagram of the numerical model. (a) Size and boundary condition. (b) Model finite element mesh.

TABLE 2: The mechanical parameters of the numerical model.

\begin{tabular}{|c|c|c|c|c|c|c|c|c|}
\hline \multirow[b]{2}{*}{ Rock mass } & \multicolumn{2}{|c|}{$\begin{array}{l}\text { Elastic } \\
\text { modulus, } \\
E(\mathrm{GPa})\end{array}$} & \multicolumn{2}{|c|}{$\begin{array}{l}\text { Poisson's } \\
\text { ratio, } \mu\end{array}$} & \multirow{2}{*}{$\begin{array}{c}\text { Cohesion, } c(\mathrm{MPa}) \\
0.65\end{array}$} & \multirow{2}{*}{$\begin{array}{c}\text { Shear modulus, } G_{2}(\mathrm{GPa}) \\
1.085\end{array}$} & \multirow{2}{*}{$\begin{array}{c}\text { Friction angle, }\left(\phi^{\circ}\right) \\
35\end{array}$} & \multirow{2}{*}{$\begin{array}{c}\text { Density, } \rho\left(k \cdot \mathrm{Nm}^{-3}\right) \\
2300\end{array}$} \\
\hline & $\begin{array}{c}E_{1} \\
3.779\end{array}$ & $\begin{array}{c}E_{2} \\
2.439\end{array}$ & $\begin{array}{c}\mu_{1} \\
0.254\end{array}$ & $\begin{array}{c}\mu_{2} \\
0.180\end{array}$ & & & & \\
\hline Joint material & 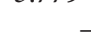 & & & - & 0.065 & - & 25 & - \\
\hline Lining & 2 & & & 27 & - & - & - & 2500 \\
\hline Bolt & 2 & & & 30 & - & - & - & 7800 \\
\hline
\end{tabular}

bolts. Similarly, with the increasing shear strength parameters, the displacement of lining is decreased firstly and then increased because the internal friction angle is the most sensitivity parameter of surrounding rocks to simulate the reinforcement effect of rock bolts equivalently.

\subsection{Comparison between Numerical and Analytical Results.} To equivalently simulate the reinforcement effect of rock bolts, the cohesion and internal friction angle of the surrounding rocks need to improve as 1.7 times and 1.2 times of the initial value according to the numerical results. Based on the parameters of the numerical model, the equivalent cohesion and internal friction angle can be calculated by equations (7) and (12). The equivalent cohesion and internal friction angle of surround rocks are $c_{0}^{\prime}=0.699 \mathrm{MPa}$ and $\varphi_{0}^{\prime}=44.231^{\circ}$, respectively. This means that the cohesion and internal friction angle of the surrounding rocks are improved by $7.5 \%$ and $26.3 \%$. From the comparison between numerical and analytical results, it can be found that the deference of internal friction angle is small, and the deference of cohesion is a little bigger. It should point out that the analytical results calculated are based on the assumption that the surrounding rocks are isotropic. However, the surrounding rocks in the numerical simulation are assumed as anisotropic material. In the other words, the internal friction angle of surrounding rocks improved after rock bolts installed may be analogous for isotropic and anisotropic rock mass tunnel.

\section{Engineering Application}

4.1. Geological Conditions. A water diversion tunnel is in the west of China, in which terrain in a whole is slightly fluctuating, and the north of the tunnel area is lower than the south, and the west of the tunnel area is lower than the east. The terrain of tunnel is slowly inclined from the northwest to the southeast, and the bedrock is mostly bare. The section of the tunnel is $46.153 \mathrm{~km}$ long, which is constructed by TBM and drilling and blasting. According to the analysis of the borehole data along the tunnel, the bottom lithology revealed by the tunnel is mainly of Devonian tuffaceous sandstone, tuff, and carbonaceous siltstone; Carboniferous andesite, calcareous glutenite, calcareous siltstone; and Hualixi period Quartz diorite and granite. The stability of a cross caverns is analyzed during excavation process in the section of drilling and blasting in this paper. The rocks in this section are mainly of Devonian tuff; the inclination angle of the rocks is $30^{\circ}$. The rock masses are layered, fresh, and intact. The stability of the surrounding rocks is very well.

4.2. Numerical Model and Calculation Parameters. The drilling and blasting section of the tunnel has a main carven and a lateral carven, which cannot be simplified as a plane strain model. It needs to establish a three-dimensional model to analyze the stability during the excavation process. Figure 9 presents the meshes of the 3D model and the size of the tunnel. The buried depth of the top surface of the 


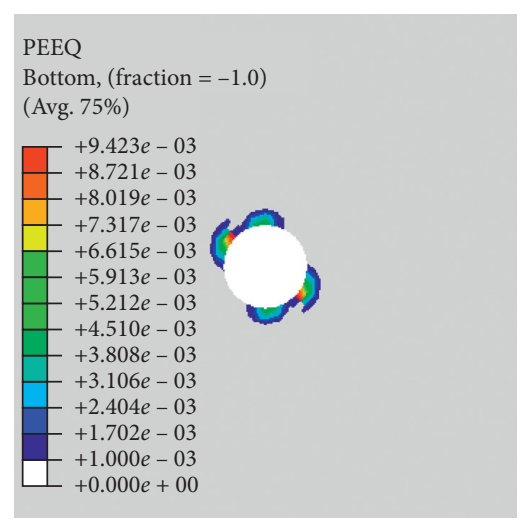

(a)

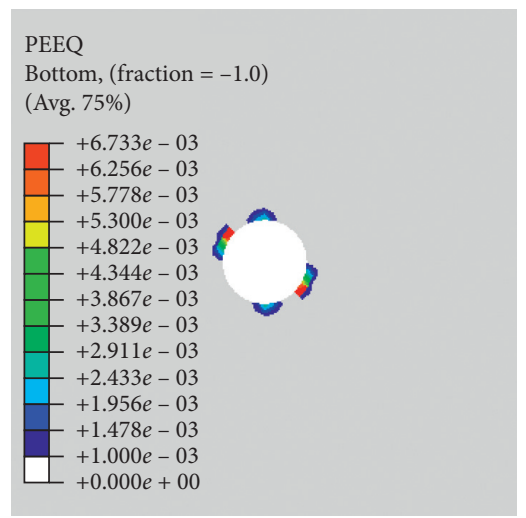

(b)

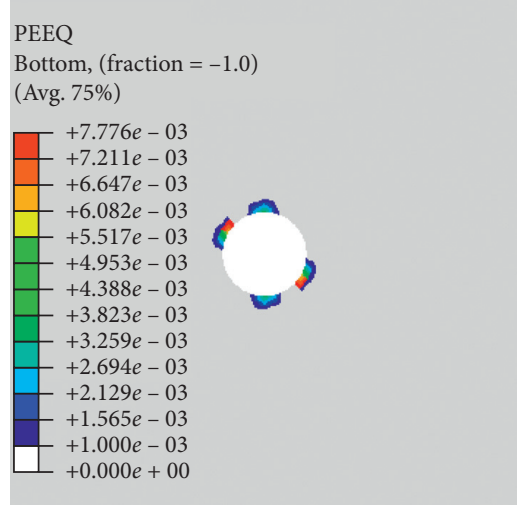

(c)

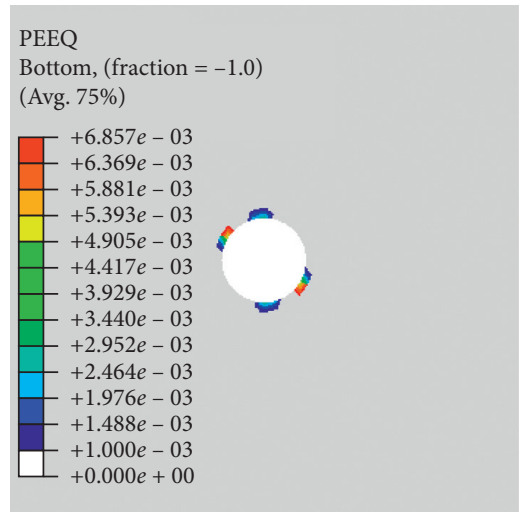

(d)

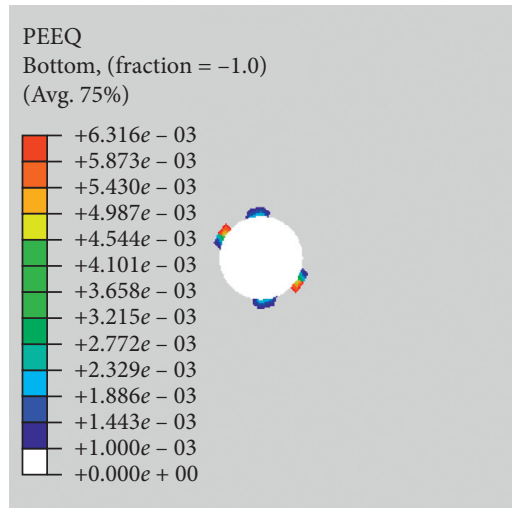

(e)

Figure 8: Plastic zone of surrounding rocks of different simulation configurations. (a) Without bolts installed. (b) With bolts installed.

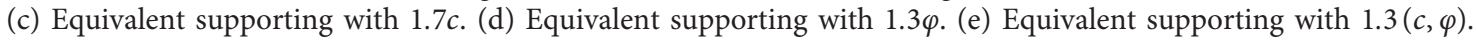

TABLE 3: Equivalent simulation results by improving the cohesion of surrounding rock mass.

\begin{tabular}{lcr}
\hline Improved parameter & \multicolumn{2}{c}{$\begin{array}{c}\text { Displacement of lining }(\mathrm{mm}) \\
\text { Horizontal displacement of arch foot }\end{array}$} \\
\hline With bolts installed & Vertical displacement of dome & 5.02 \\
Without bolts installed & 17.16 & 7.76 \\
$1.1 c$ & 19.14 & 6.52 \\
$1.2 c$ & 18.18 & 6.24 \\
$1.3 c$ & 17.86 & 6.06 \\
$1.4 c$ & 17.61 & 5.88 \\
$1.5 c$ & 17.42 & 5.72 \\
$1.6 c$ & 17.30 & 5.64 \\
$1.7 c$ & 17.23 & 5.56 \\
$1.8 c$ & 17.16 & 5.48 \\
$1.9 c$ & 17.09 & 5.40 \\
$2.0 c$ & 17.02 & 5.32 \\
\hline
\end{tabular}

numerical model is $176.7 \mathrm{~m}$. Axial $Y$ is the gravity direction of the rock masses, and axial $X$ and $Z$ are the axial line of the main carven and lateral carven, respectively. The solid elements are adopted in this model, and the element type is C3D8R. The $X$ and $Z$ direction of the model is horizontally constrained, and the bottom of the model is vertically constrained. The modified jointed material model is adopted in the numerical simulation for the rock masses, and the Mohr-Coulomb model is adopted for the simulation of lining. In the whole simulations, the rock bolts are equivalently simulated by improving the shear strength parameters of the surrounding rocks $(1.1(c, \varphi))$, and influence of the rock type is ignored. According to the geological data, mechanical parameters of the rocks and lining are listed in Table 6. The process of tunnel excavation can be simulated by two configurations: (1) only supported by lining and (2) equivalently supported by rock bolts and lining. 
TABLE 4: Equivalent simulation results by improving the friction angle of surrounding rock mass.

\begin{tabular}{lcr}
\hline Improved parameter & \multicolumn{2}{c}{$\begin{array}{c}\text { Displacement of lining (mm) } \\
\text { Horizontal displacement of arch foot }\end{array}$} \\
\hline With bolts installed & Vertical displacement of dome & 5.02 \\
Without bolts installed & 17.16 & 7.76 \\
$1.1 \varphi$ & 19.14 & 5.96 \\
$1.2 \varphi$ & 17.09 & 5.22 \\
$1.3 \varphi$ & 16.73 & 4.80 \\
$1.4 \varphi$ & 16.42 & 4.68 \\
$1.5 \varphi$ & 16.19 & 4.56 \\
$1.6 \varphi$ & 16.03 & 4.50 \\
$1.7 \varphi$ & 16.00 & 4.64 \\
$1.8 \varphi$ & 16.08 & 4.70 \\
$1.9 \varphi$ & 16.18 & 4.80 \\
$2.0 \varphi$ & 16.28 & 4.82 \\
\hline
\end{tabular}

TABLE 5: Equivalent simulation results by improving cohesion and friction angle of surrounding rock mass.

\begin{tabular}{lcc}
\hline Improved parameter & \multicolumn{2}{c}{ Displacement of lining (mm) } \\
& Vertical displacement of dome & Horizontal displacement of arch foot \\
\hline With bolts installed & 17.16 & 5.02 \\
Without bolts installed & 19.14 & 7.76 \\
$1.1(c, \varphi)$ & 17.31 & 5.66 \\
$1.2(c, \varphi)$ & 16.48 & 4.88 \\
$1.3(c, \varphi)$ & 16.35 & 4.80 \\
$1.4(c, \varphi)$ & 16.16 & 4.66 \\
$1.5(c, \varphi)$ & 16.02 & 4.60 \\
$1.6(c, \varphi)$ & 16.09 & 4.55 \\
$1.7(c, \varphi)$ & 16.20 & 4.72 \\
$1.8(c, \varphi)$ & 16.28 & 4.82 \\
$1.9(c, \varphi)$ & 16.28 & 4.84 \\
$2.0(c, \varphi)$ & 16.29 & 4.84 \\
\hline
\end{tabular}

\subsection{Stability Analysis of Tunnel Excavation}

\subsubsection{Analysis of the Main Cavern Excavation.} Figures 10 and 11 show the maximum and minimum principle stress of the surrounding rocks after the main cavern is excavated. The maximum principle stress appears at the floor and the middle sidewall of the tunnel. For the equivalently bolted rock masses, the maximum principle stress is compressive strength; however, the tensile stress appears in the surrounding rocks without rock bolts are applied. Stress concentration may appear at the junction of the sidewall and bottom floor, and the maximum compressive stress is about $16 \mathrm{MPa}$. The compressive stress at the roof of the tunnel is a little bigger, and the stress is about $12 \mathrm{MPa}$. Figure 12 shows the vertical displacement of the surrounding rocks after the excavation of main cavern. For the equivalently bolted rock masses, the vertical displacements of the roof and floor are $8 \mathrm{~mm}$ and $3.45 \mathrm{~mm}$, respectively. However, for the surrounding rocks without rock bolts being applied, the vertical displacement of the roof and floor is bigger. It is demonstrated that the equivalent anchoring method can control the deformation of the surrounding rock masses. Figure 13 presents the plastic zone of the surrounding rocks, for the equivalently bolted rock masses, the plastic zone only appears at the middle of the sidewall, and the range of the plastic zone is small. However, for the surrounding rocks without rock bolts being applied, the plastic zone appears at the middle of all sidewalls, and the floor of the tunnel. The range of the plastic zone is wide.

4.3.2. Analysis of the Lateral Cavern Excavation. Figures 14 and 15 show the maximum and minimum principle stress after the lateral cavern is excavated. For the zone of the lateral cavern, the maximum principle stress appears at the roof of the cross section between the main cavern and lateral cavern, which the tensile stress may emerge in this area. It should note that the tensile failure will be occurred. After the lateral cavern is excavated, the compressive stress at the sidewall of the lateral cavern is about $9 \mathrm{MPa}$, which the compressive failure may be occurred. Figure 16 shows the plastic zone of the surrounding rocks after the lateral cavern is excavated. For the equivalently bolted rock masses, the plastic zone only appeared at sidewall of the cross section between the main cavern and lateral cavern. It is closer to the actual construction of the tunnel. It demonstrates that the equivalent anchoring method can reflect the failure zone of the surrounding rocks during the tunnel excavation. Meanwhile, 17 shows that the vertical displacement of the lateral cavern roof is $1.39 \mathrm{~cm}$ for 


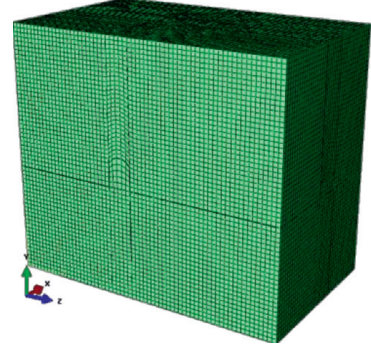

(a)

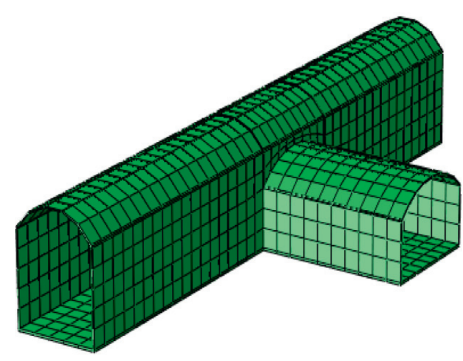

(c)

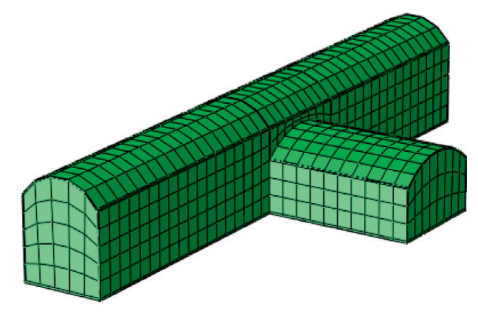

(b)

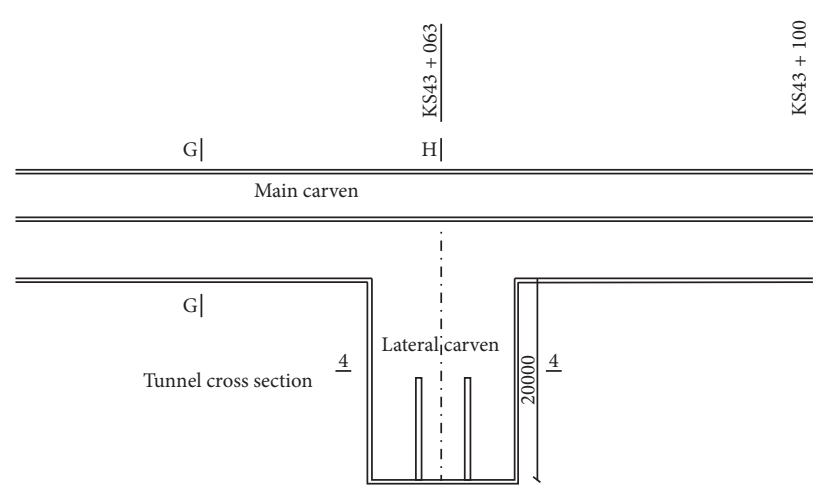

(d)

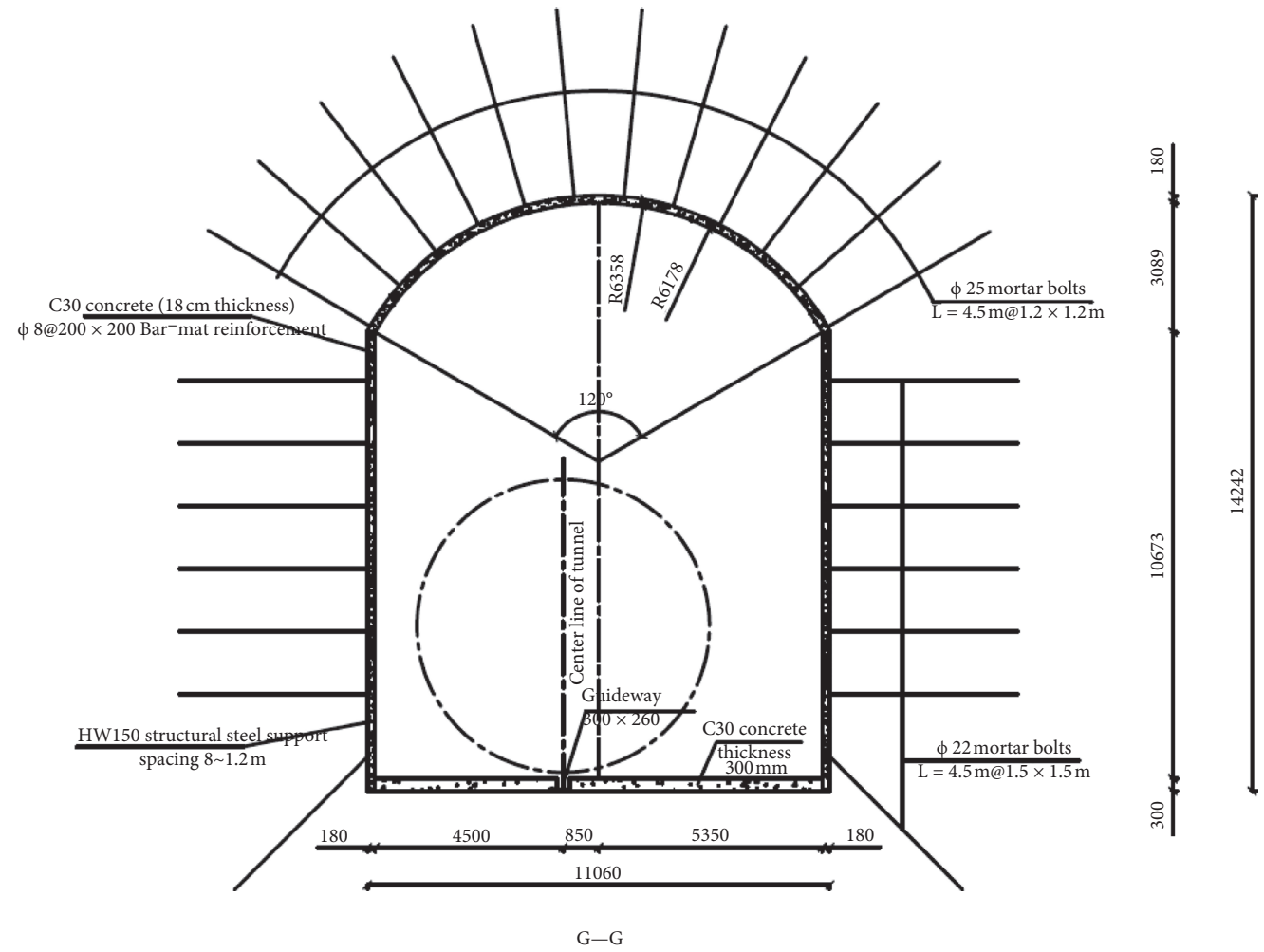

(e)

FIgure 9: Continued. 


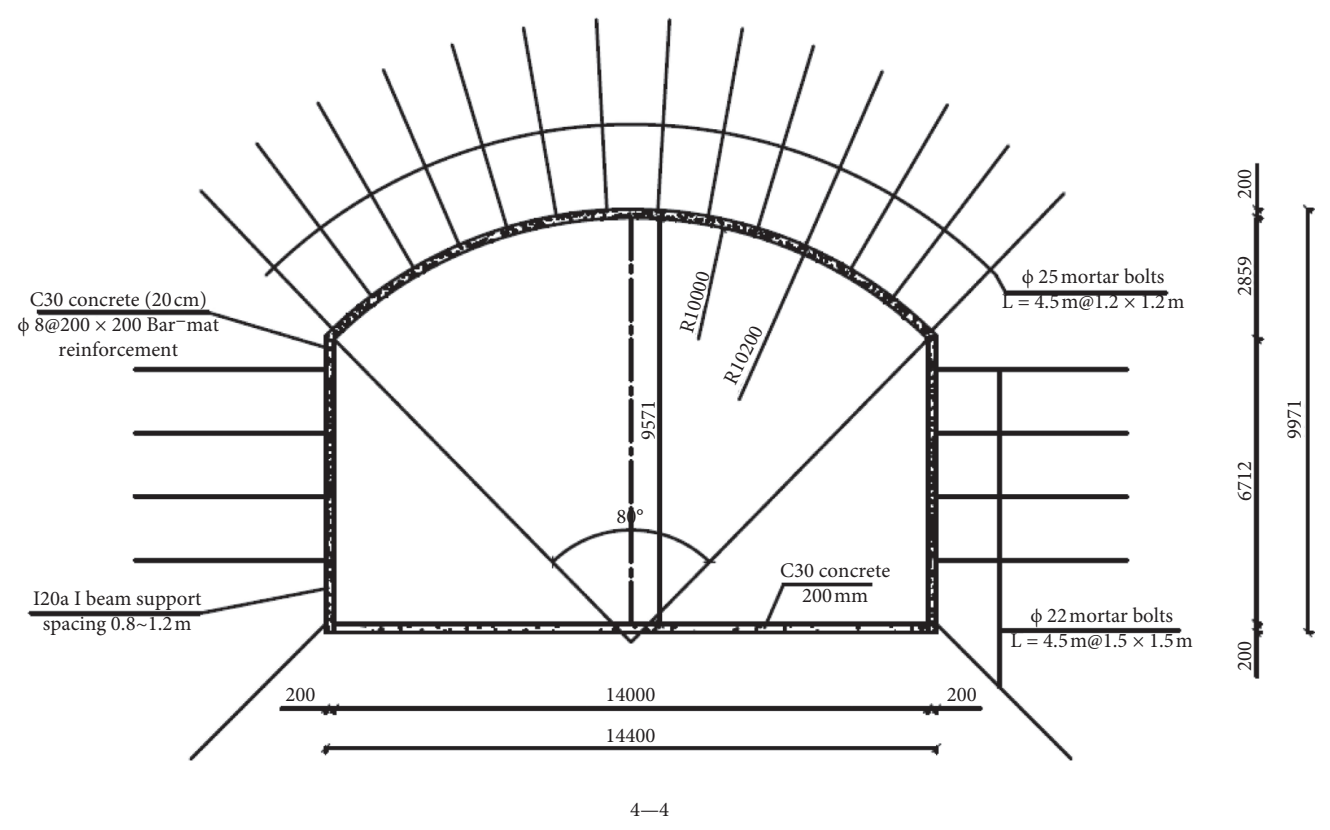

(f)

Figure 9: Diagram of 3D numerical model and tunnel size. (a) 3D numerical model. (b) Meshes of tunnel. (c) Meshes of lining. (d) Diagram of tunnel cross section. (e) Size of main carven. (f) Size of lateral carven.

TABLE 6: The mechanical parameters of the numerical model.

\begin{tabular}{|c|c|c|c|c|c|c|c|c|}
\hline \multirow{2}{*}{$\begin{array}{l}\text { Material } \\
\text { Rock mass }\end{array}$} & \multicolumn{2}{|c|}{$\begin{array}{c}\text { Elastic } \\
\text { modulus, } \\
E(\mathrm{GPa})\end{array}$} & \multicolumn{2}{|c|}{$\begin{array}{l}\text { Poisson's } \\
\text { ratio, } \mu\end{array}$} & \multirow{2}{*}{$\begin{array}{c}\text { Cohesion, } c(\mathrm{MPa}) \\
0.70\end{array}$} & \multirow{2}{*}{$\begin{array}{c}\text { Shear modulus, } G_{2}(\mathrm{GPa}) \\
3.60\end{array}$} & \multirow{2}{*}{$\begin{array}{c}\text { Friction angle, }\left(\varphi^{\circ}\right) \\
43\end{array}$} & \multirow{2}{*}{$\begin{array}{c}\text { Density, } \rho\left(\mathrm{kN} \cdot \mathrm{m}^{-3}\right) \\
2600\end{array}$} \\
\hline & $\begin{array}{l}E_{1} \\
11\end{array}$ & $\begin{array}{c}E_{2} \\
7.5\end{array}$ & $\begin{array}{c}\mu_{1} \\
0.30\end{array}$ & $\begin{array}{c}\mu_{2} \\
0.20\end{array}$ & & & & \\
\hline Joint material & \multicolumn{2}{|c|}{-} & \multicolumn{2}{|c|}{-} & 0.070 & - & 28 & - \\
\hline Lining & \multicolumn{2}{|c|}{30} & \multicolumn{2}{|c|}{0.25} & 58.7 & - & 2.38 & 2600 \\
\hline
\end{tabular}

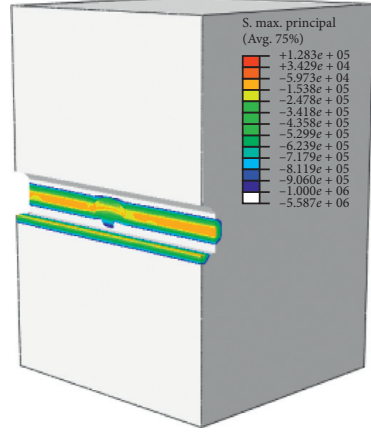

(a)

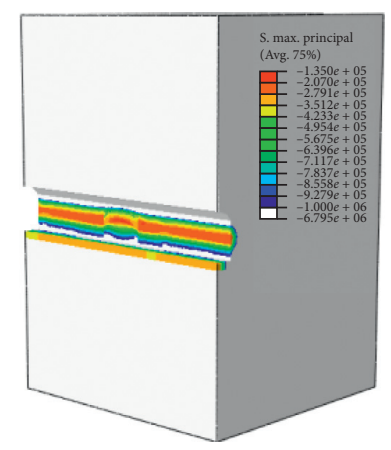

(b)

Figure 10: Maximum principle stress after main cavern is excavated ( $\mathrm{Pa}$ ). (a) Without rock bolts. (b) Equivalently anchored.

the surrounding rocks without rock bolts being applied. However, for the equivalently bolted rock masses, the vertical displacement is $1.20 \mathrm{~cm}$.

4.3.3. Mechanical Analysis of the Lining. Figures 18 and 19 are the principle stress of the lining. Figure 18 shows that the most area of the lining is under the condition of tension, and the maximum tensile stress is less than $1.78 \mathrm{MPa}$. Figure 19 shows that the compressive stress of the color area of the lining is bigger than $16.7 \mathrm{MPa}$, and the maximum compressive stress may be occurring at the cross section between the roof and sidewall of lining, and the cross section between the sidewall and floor of lining. 


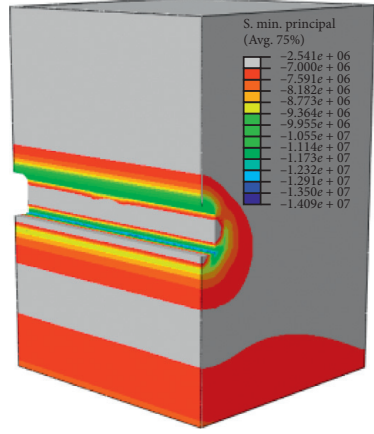

(a)

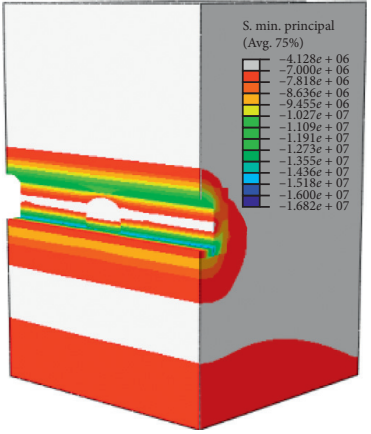

(b)

Figure 11: Minimum principle stress after main cavern is excavated (Pa). (a) Without rock bolts. (b) Equivalently anchored.

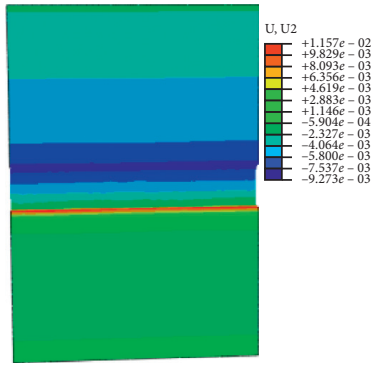

(a)

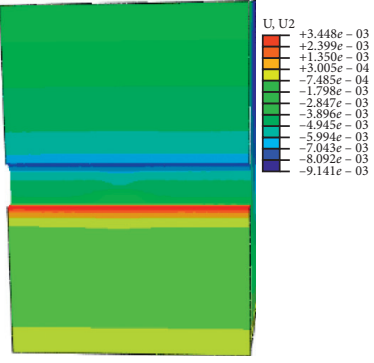

(b)

FIGURE 12: Displacement of $Y$ direction after main cavern is excavated (m). (a) Without rock bolts. (b) Equivalently anchored.

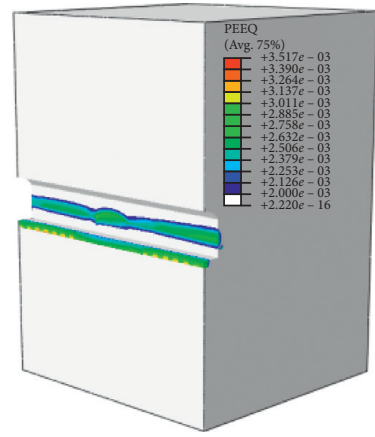

(a)

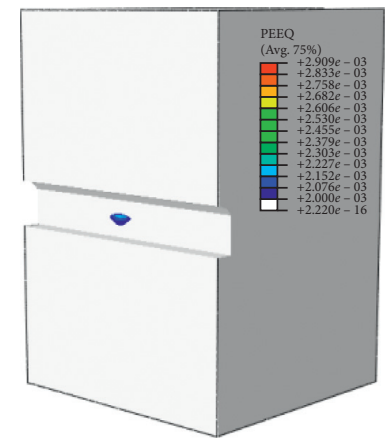

(b)

FiguRE 13: Equivalent plastic zone after main cavern is excavated. (a) Without rock bolts. (b) Equivalently anchored.

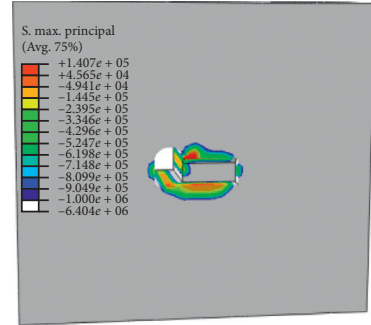

(a)

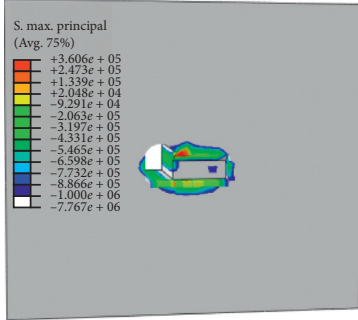

(b)

FIgURE 14: Maximum principle stress after lateral cavern is excavated (Pa). (a) Without rock bolts. (b) Equivalently anchored. 


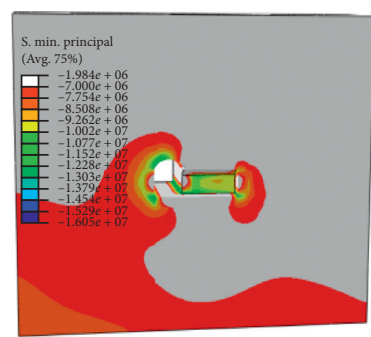

(a)

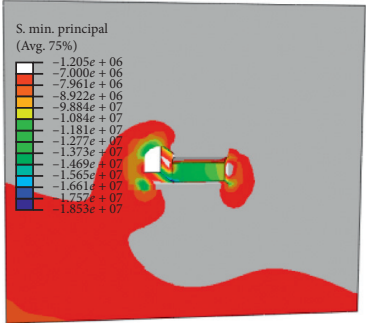

(b)

FIGURE 15: Minimum principle stress after lateral cavern is excavated (Pa). (a) Without rock bolts. (b) Equivalently anchored.

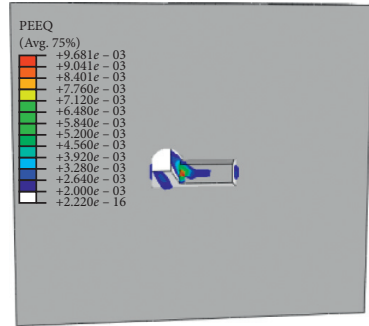

(a)

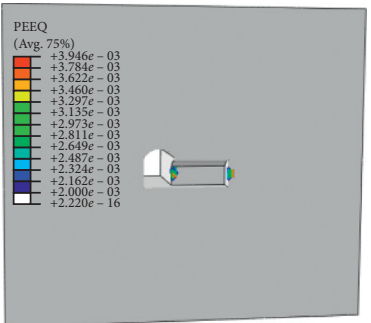

(b)

FIgURE 16: Equivalent plastic zone after lateral cavern excavated. (a) Without rock bolts. (b) Equivalently anchored.

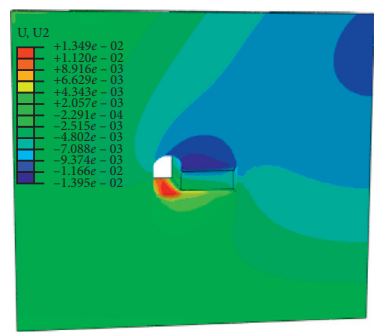

(a)

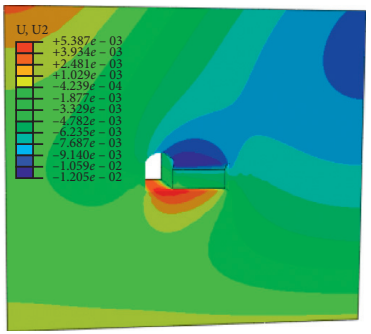

(b)

Figure 17: Displacement of $Y$ direction after lateral cavern is excavated (m). (a) Without rock bolts. (b) Equivalently anchored.

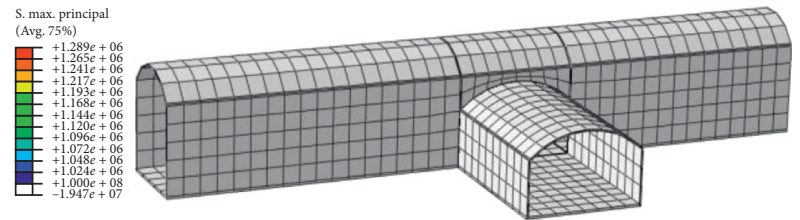

(a)

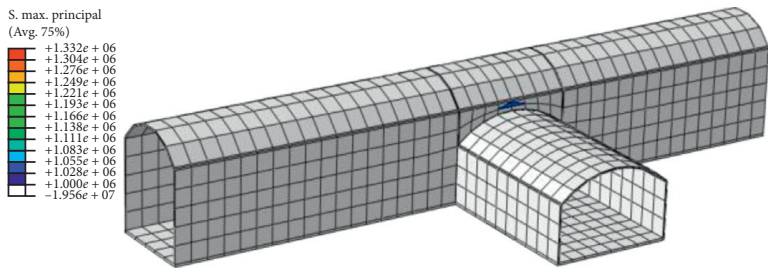

(b)

Figure 18: Maximum principle stress of lining after excavation (Pa). (a) Without rock bolts. (b) Equivalently anchored.

Figure 20 presents the plastic zone of lining. For the equivalently bolted rock masses, the plastic zone of lining only appears at the sidewall of the cross section between the main cavern and lateral cavern, and the range of the plastic zone is small. For the surrounding rocks without rock bolts being applied, the range of the plastic zone is large. Figure 21 shows the vertical displacement of lining, which is similar to that of tunnel in Figure 17. 


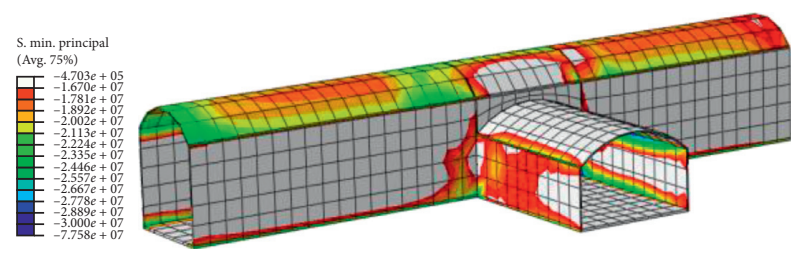

(a)

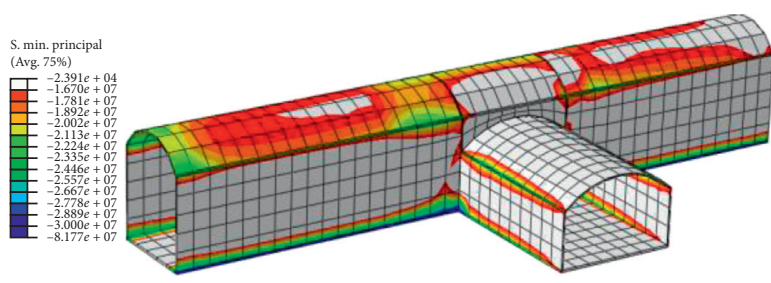

(b)

FIgURE 19: Minimum principle stress of lining after excavation (Pa). (a) Without rock bolts. (b) Equivalently anchored.

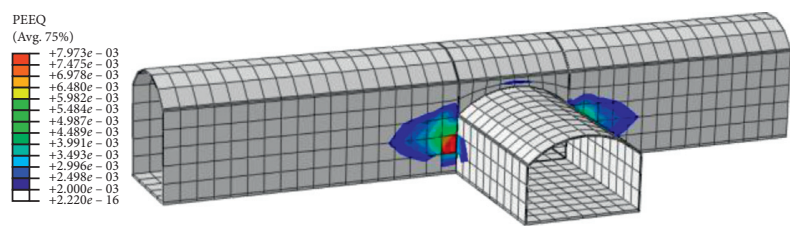

(a)

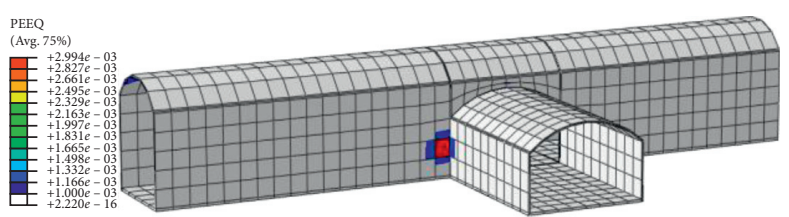

(b)

Figure 20: Equivalent plastic zone of lining after excavation. (a) Without rock bolts. (b) Equivalently anchored.

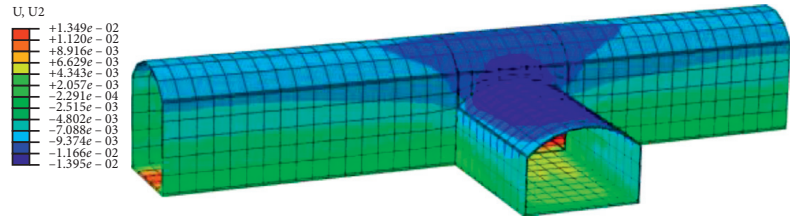

(a)

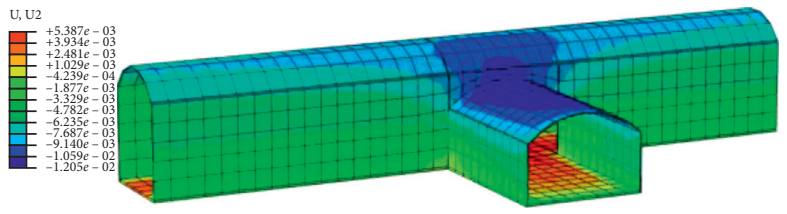

(b)

Figure 21: Displacement of $Y$ direction of lining after excavation (m). (a) Without rock bolts. (b) Equivalently anchored.

\section{Conclusions}

The reinforcement effect of surrounding rock masses installed with rock bolts is equivalently simulated based on the assumption that the constitutive model of the jointed rock masses is anisotropic. The equivalent anchoring method of the jointed rock mass tunnel is proposed, and the method is applied to the stability analysis of a division tunnel in Western China. Some conclusions can be obtained from the studies in this paper.

(1) Considering the anisotropic properties of the layered rocks, the elastic matrix of the jointed material model is modified. The model verification shows that the modified jointed material model can reflect the anisotropic properties of the layered rocks.

(2) Based on the modified jointed material model, the equivalent anchoring method of the jointed rock mass tunnel is numerically studied. The results of a series of numerical simulations show that the reinforcement effect of rock bolts can be equivalently simulated by improving the shear strength parameters of surrounding rocks. In order to simulate the reinforcement effect of rock bolts, the cohesion and internal friction angle of the surrounding rocks need to improve as 1.7 times and 1.2 times of the initial value. The shear strength parameters of surrounding rocks, improved 1.1 times the initial value, can accurately simulate the reinforcement effect of rock bolts.

(3) The excavation process of a division tunnel in Western China is numerically studied in this paper. The simulation results show that the equivalent anchoring method can reflect the reinforcement effect of the rock bolts. The numerical results are close to the actual conditions of the tunnel construction. It demonstrates that the equivalent anchoring method can be used to the simulation of $3 \mathrm{D}$ tunnel construction process. It solves the problem of the simulation method of rock bolts in three dimensions and many rock bolts applied in three-dimensional model.

\section{Data Availability}

The data used to support the findings of this study are included within the article.

\section{Conflicts of Interest}

The authors declare no conflicts of interest. 


\section{References}

[1] K. Spang and P. Egger, "Action of fully-grouted bolts in jointed rock and factors of influence," Rock Mechanics and Rock Engineering, vol. 23, no. 3, pp. 201-229, 1990.

[2] A. J. Hyett, W. F. Bawden, and R. D. Reichert, "The effect of rock mass confinement on the bond strength of fully grouted cable bolts," International Journal of Rock Mechanics and Mining Sciences \& Geomechanics Abstracts, vol. 29, no. 5, pp. 503-524, 1992.

[3] M. Marence and G. Swoboda, "Numerical model for rock bolts with consideration of joint movement," Rock Mechanics and Rock Engineering, vol. 28, no. 3, pp. 145-165, 1995.

[4] F. Pellet and P. Egger, "Analytical model for the mechanical behaviour of bolted rock joints subjected to shearing," Rock Mechanics and Rock Engineering, vol. 29, no. 2, pp. 73-97, 1996.

[5] X. L. Cai and D. A. Zhao, "Probe into simulation of the bolt function by increasing geometrical parameters in tunnel calculation," Journal of Lanzhou Jiaotong University: Nature Science, vol. 23, no. 1, pp. 10-14, 2004, in Chinese.

[6] F. Ahmad and H. Soroush, "A theoretical approach for analysis of the interaction between grouted rockbolts and rock masses," Tunnelling and Underground Space Technology, vol. 20, pp. 333-343, 2005.

[7] M. Ghadimi, K. Shahriar, and H. Jalalifar, "A new analytical solution for the displacement of fully grouted rock bolt in rock joints and experimental and numerical verifications," Tunnelling and Underground Space Technology, vol. 50, pp. 143$151,2015$.

[8] S.-H. Chen, C.-H. Fu, and S. Isam, "Finite element analysis of jointed rock masses reinforced by fully-grouted bolts and shotcrete lining," International Journal of Rock Mechanics and Mining Sciences, vol. 46, no. 1, pp. 19-30, 2009.

[9] B. Denise, M. Samir, and B. Patrick, "A numerical approach for design of bolt-supported tunnels regarded as homogenized structures," Tunnelling and Underground Space Technology, vol. 29, pp. 533-546, 2009.

[10] T. C. Carranza, "Analytical and numerical study of the mechanics of rock bolt reinforcement around tunnels in rock masses," Rock Mechanics and Rock Engineering, vol. 42, pp. 175-228, 2009.

[11] S. Maghous, D. Bernaud, and E. Couto, "Three-dimensional numerical simulation of rock deformation in bolt-supported tunnels: a homogenization approach," Tunnelling and Underground Space Technology, vol. 31, pp. 68-79, 2012.

[12] Y. Cai, Y. Jiang, I. Djamaluddin, T. Iura, and T. Esaki, “An analytical model considering interaction behavior of grouted rock bolts for convergence-confinement method in tunneling design," International Journal of Rock Mechanics and Mining Sciences, vol. 76, pp. 112-126, 2015.

[13] K. Zhang, G. Zhang, R. Hou, Y. Wu, and H. Zhou, "Stress evolution in roadway rock bolts during mining in a fully mechanized longwall face, and an evaluation of rock bolt support design," Rock Mechanics and Rock Engineering, vol. 48, no. 1, pp. 333-344, 2015.

[14] L. He, X. M. An, and Z. Y. Zhao, "Fully grouted rock bolts: an analytical investigation," Rock Mechanics and Rock Engineering, vol. 48, no. 3, pp. 1181-1196, 2015.

[15] L. P. Srivastava and M. Singh, "Effect of fully grouted passive bolts on joint shear strength parameters in a blocky mass," Rock Mechanics and Rock Engineering, vol. 48, no. 3, pp. 1197-1206, 2015.

[16] S. Ma, Z. Zhao, W. Nie, and Y. Gui, "A numerical model of fully grouted bolts considering the tri-linear shear bond-slip model," Tunnelling and Underground Space Technology, vol. 54, pp. 73-80, 2016.

[17] B. Indraratna and P. K. Kaiser, "Analytical model for the design of grouted rock bolts," International Journal for $\mathrm{Nu}$ merical and Analytical Methods in Geomechanics, vol. 14, no. 4, pp. 227-251, 1990.

[18] R. Osgouir, Ground reaction curve of reinforced tunnel using a new elasto-plastic model, Ph.D thesis, The Technical University of Turin, Turin, Italy, 2006.

[19] Q. Meng, H. B. Zhao, and Z. L. Ru, "Equivalent strength parameters and reliability analysis of circular tunnel with rock bolt supporting," Rock and Soil Mechanics, vol. 35, no. S1, pp. 437-442, 2014, in Chinese.

[20] S. H. Kim, S. Pelizza, and J. S. Kim, "A study of strength parameters in the reinforced ground by rock bolts," Tunnelling and Underground Space Technology, vol. 21, no. 3-4, pp. 378-379, 2006.

[21] A. Bobet and H. H. Einstein, "Tunnel reinforcement with rockbolts," Tunnelling and Underground Space Technology, vol. 26, no. 1, pp. 100-123, 2011.

[22] F. A. Donath, "Experimental study of shear failure in anisotropic rocks," Geological Society of America Bulletin, vol. 72, no. 6, pp. 985-989, 1961.

[23] F. G. Horino and M. L. Ellickson, A Method of Estimating Strength of Rock Containing Planes of Weakness, Vol. 7449, United States Bureau of Mines Repository Investigation, Washington, DC, USA, 1970.

[24] R. Mclamore and K. E. Gray, "The mechanical behavior of anisotropic sedimentary rocks," Journal of Engineering for Industry, vol. 89, no. 1, pp. 62-73, 1967.

[25] T. Ramamurthy, "Strength and modulus responses of anisotropic rocks," in Comprehensive Rock Engineering, J. A. Hudson, Ed., vol. 1, pp. 313-329, Pergamon Press, Oxford, UK, 1993.

[26] Y. M. Tien and M. C. Kuo, "A failure criterion for transversely isotropic rocks," International Journal of Rock Mechanics and Mining Sciences, vol. 38, no. 3, pp. 399-412, 2001.

[27] Y. M. Tien and P. F. Tsao, "Preparation and mechanical properties of artificial transversely isotropic rock," International Journal of Rock Mechanics and Mining Sciences, vol. 37, no. 6, pp. 1001-1012, 2000.

[28] Y. M. Tien, M. C. Kuo, and C. H. Juang, "An experimental investigation of the failure mechanism of simulated transversely isotropic rocks," International Journal of Rock Mechanics and Mining Sciences, vol. 43, no. 8, pp. 1163-1181, 2006.

[29] B. Amadei, "Importance of anisotropy when estimating and measuring in situ stresses in rock," International Journal of Rock Mechanics and Mining Sciences \& Geomechanics Abstracts, vol. 33, no. 3, pp. 293-325, 1996.

[30] B. Amadei and E. Pan, "Gravitational stresses in anisotropic rock masses with inclined strata," International Journal of Rock Mechanics and Mining Sciences \& Geomechanics Abstracts, vol. 29, no. 3, pp. 225-236, 1992.

[31] C.-S. Chen, E. Pan, and B. Amadei, "Determination of deformability and tensile strength of anisotropic rock using Brazilian tests," International Journal of Rock Mechanics and Mining Sciences, vol. 35, no. 1, pp. 43-61, 1998.

[32] Z. Z. Liang, C. A. Tang, H. X. Li, T. Xu, and T. H. Yang, "A numerical study on failure process of transversely isotropic rock subjected to uniaxial compression," Rock and Soil Mechanics, vol. 26, no. 1, pp. 57-62, 2005, in Chinese.

[33] A. Ghazvinian, R. G. Vaneghi, M. R. Hadei, and M. J. Azinfar, "Shear behavior of inherently anisotropic rocks," 
International Journal of Rock Mechanics and Mining Sciences, vol. 61, pp. 96-110, 2013.

[34] Y. Li, C. A. Tang, D. Li, and C. Wu, "A new shear strength criterion of three-dimensional rock joints," Rock Mechanics and Rock Engineering, vol. 53, no. 3, pp. 1477-1483, 2020.

[35] X. M. Zhang, Anisotropic characteristic of rock material and its effect on stability of tunnel surrounding rock, Ph.D thesis, Central South University, Changsha, China, 2007.

[36] H. Dulacska, "Dowel action of reinforcement crossing cracks in concrete," Journal of the American Concrete Institute, vol. 69, no. 12, pp. 754-757, 1972. 